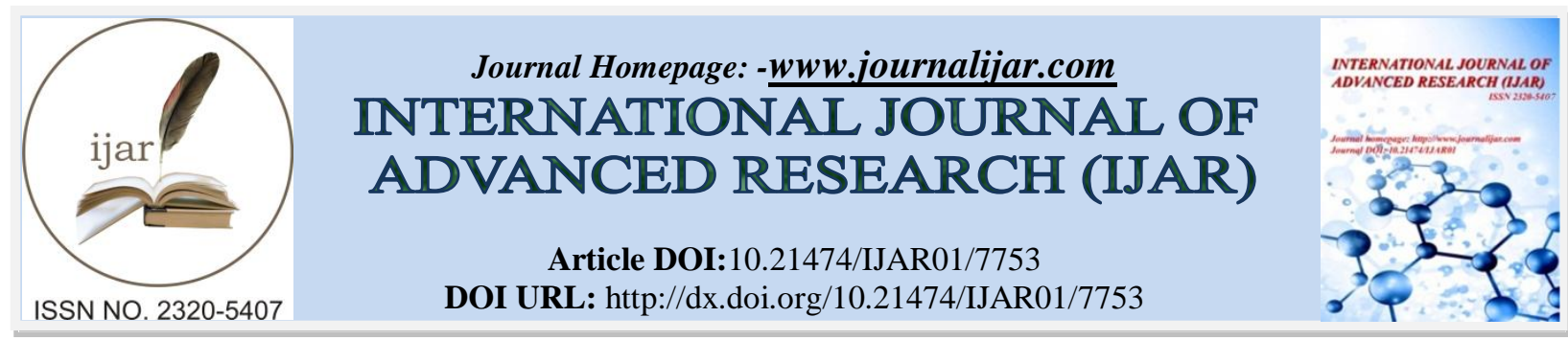

RESEARCH ARTICLE

\title{
EXTREME WATER CONFINEMENT AMIDST SUPERHYDROPHILIC SU8 MICROPATTERNED WALLS.
}

\author{
StefaniaD'Amone ${ }^{1}$, Ilaria Elena Palamà ${ }^{1}$, Alessio Mezzi $^{2}$, Giuseppe Gigli ${ }^{1,3}$ and Barbara Cortese ${ }^{4}$. \\ 1. CNR-NANOTEC, via Monteroni, Lecce, 73100, Italy. \\ 2. ISMN-CNR Area della Ricerca di Roma,Via Salaria km 29,300 00015 Monterotondo (Rome) Italy \\ 3. Department of Mathematics and Physics, University of Salento, Lecce, Italyisep: \\ 4. CNR- NANOTEC, University La Sapienza, P.zle A. Moro, Roma, 00185, Italy.
}

\section{Manuscript Info}

(........................

Manuscript History

Received: 24 July 2018

Final Accepted: 30 August 2018

Published: September 2018

Keywords:-

Wettability

confinementPlasma

treatmentSuperhydrophilic

SuperoleophobicUnderwater behaviour.

\begin{abstract}
Control of motion of drops on solid surfaces and their mechanism is relevant in many nanotechnology processes and water vapour harvesting practices. Biomimetic strategies comprise designing topographic and chemical heterogeneities on solid surfaces, which can pin and steer drops towards required specific locations. Herein, a simple approach to realize "confined smart" liquid drops on surfaces with hydrophilic regions surrounded by superhydrophilic boundaries upon applying a $\mathrm{CF}_{4} / \mathrm{Ar}$ plasma to a microstructured silicon substrate is presented. The key property of confinement was controlled topographically under simple selective patterning of SU-8 and chemically by plasma modification. Surface chemical and morphological modification of plasma on the SU-8 patterned silicon surfaces were evaluated. Moreover behaviour at the underwater solid/ liquid interface and in underwater oil wettability were investigated. According to this approach, the proposed platform is suitable for biological and chemical applications, for capturing drops for Lab-on-achip devices or water harvesting applications.
\end{abstract}

Copy Right, IJAR, 2018,. All rights reserved.

\section{Introduction:-}

Controlling the motion of drops on solid surfaces has long attracted attention in the field of nanotechnology with remarkable progress in the recent years. The wettability of chemically heterogeneous and topographically rough surfaces and the pioneering concept of constructing superhydrophilic and underwater superoleophobic surfaces is a key feature in many applications such as biomedical microdevices (Gogolides et al., 2015), lab-on-a-chip (Farshchian et al., 2012; Sackmann et al., 2014), biosensors (Bogue, 2007; Kim et al., 2013), and antifouling applications (Brown and Bhushan, 2015). Wetting transitions are highly relevant in superhydrophobic and oleophobic applications (Hejazi et al., 2012; Chen et al., 2015b). The well-known classical theories of wetting describe which micro/nano-size topographical features and chemically heterogeneous surfaces are required to control wettability (Cortese et al., 2008; Herminghaus et al., 2008; Cortese and Morgan, 2012; Hao et al., 2016). Nevertheless this process is complicated even with rather simple surface topographies, e.g., channels with a rectangular cross-section and identical surface chemistry showed different wetting morphologies which depended on the pinning of the contact line along 
the geometrical border line of the surface (Seemann et al., 2005). When it comes to underwater superoleophobicity, the geometrical demand is for textured surfaces of high surface energy, generally referred to as the "fish-scale or sharkskin effect" (Tuteja et al., 2008; Bixler and Bhushan, 2013; Nishimoto and Bhushan, 2013; Palamà et al., 2014; Chen et al., 2015a; Jiang et al., 2015; Nosonovsky and Bhushan, 2016; Yong et al., 2017). However, despite numerous studies reporting on chemically or physically modified surfaces of controlled wettability and underwater oleophobicity, current methods still rely on complicated multistep experimental procedures or expensive materials. Therefore a simple step and low cost fabrication method for underwater superoleophobic surfaces are a highly desired topic. Besides, no tactic involves fabrication of topographically structured surfaces with confined control over wettability and the wetting transitions of nonpolar liquids on roughened textured substrates remains unclear.

Epoxy-based negative photoresist SU-8 is a common structural component and material of choice in device manufacturing, because of its advantageous properties as excellent mechanical properties, thermal stability, etching resistance and chemically stability against several acids and bases (Cortese et al., 2014). Through simple photolithographic process, patterning of SU-8 presents the capability to produce structures with high aspect ratio and multilevel processing to create complex three-dimensional structures (Lorenz et al., 1997; Caputo et al., 2009). These advantages combined with its biocompatibility may allow to fabricate point of care analysis and diagnostics devices (Campo and Greiner, 2007).However, the hydrophobicity/oleophilicity of SU-8 imposes a limitation in surface wetting and biofouling causing unsuitableness in essential applications as in biomedical and industrial fields (Nordström et al., 2004; Nemani et al., 2013). Moreover the merits of underwater oleophilicity/oleophobicity for SU-8 substrates and the underlying role played by underwater interface characteristics are yet to be explored. Plasma treatment is an easy way to realize wettability transition (Seemann et al., 2005; Xu et al., 2007; Bixler and Bhushan, 2013). The advantages of using a plasma surface modification technique lie on the fact that it is a fast, standardized, environmentally friendly process. Additionally, during the treatment process, chemically reactive functionality can be introduced onto otherwise non-reactive substrates to change the physicochemical properties of the substrate surface.

Herein, we show that through plasma modification, geometrically engineered micropost-patterned SU-8 surfaces, are significant for regulating solid/liquid interface interactions and can allow water confinement. Our method consists on realizing a desired SU-8 pattern by photolithography on a tetraethylorthosilicate (TEOS) surface and applying a plasma flux of a combination of $\mathrm{CF}_{4}$ and subsequent Argon (Ar) plasma using a RIE (Reactive Ion Etching) system. The result is a micropost-structured surface in which specific areas are hydrophilic surrounded by superhydrophilic boundaries that perform the function to confine the liquid inside the hydrophilic region. Furthermore our strategy takes into account the effect of geometrical topographic structures in the complex underwater environment. In our earlier study we observed that wetting transitions occurred due to the presence of air pockets and the composite Cassie-Baxter (CB) and homogeneous Wenzel (W) wetting states in underwater oleophobicity(Sobiesierski et al., 2015). In this paper, we demonstrate the effect of surface topography on wetting transition of an underwater solid-oilwater interface by showing that the chemical effect on an immersed solid surface can drive the transition from $\mathrm{W}$ to $\mathrm{CB}$ state without complicated geometries. By comparing the solid fraction, the effect of the geometry size and hierarchy of the microstructures on water and oil contact angles was discussed. The hydrophilization of the engineered substrates was analysed by contact angle measurements and topographic imaging with an atomic force microscope (AFM). X-ray Photoelectron Spectroscopy (XPS) measurements were carried out in order to investigate the surface chemical modifications occurred after plasma treatment. Underwater oil contact angle investigations were conducted to evaluate the oil wettability properties of the plasma irradiated samples. The extreme wetting behaviour can be used to apply underwater wettability patterns and as a biomimetic coating to prevent contamination of the underwater hull of the ships by biological and organic contaminants, including oil. Moreover, this simple and fast process can be utilized for the development of a liquid confined SU-8-based device for the Bio-MEMS applications and oil water separation processes.

\section{Materials and Methods:- Preparation of SU-8 Masters}


Substrates of TEOS $\left(\mathrm{Si}\left(\mathrm{OC}_{2} \mathrm{H}_{5}\right)_{4}\right)$ were used. Patterns were prepared using SU-8 2010, purchased from MicroChem Corp., on the silicon wafer substrates. First, the substrates were cleaned in acetone and 2propanol and subsequently dried with $\mathrm{N}_{2}$ airflow. Each sample was spun at an acceleration such as to obtain the desired height of about $25 \mu \mathrm{m}$. The samples were soft baked and post-exposure baked on hotplates and allowed to cool down in order to improve adhesion of SU-8 to the substrate. The wafers were then developed by immerging the substrates in SU-8 developer and 2-propanol.

\section{Plasma Treatment}

The flat and micropost-structured SU-8/TEOS samples were treated in $\mathrm{CF}_{4}$ and Ar plasmas generated in a RIE IONVAC inductively coupled (ICP) plasma reactor (PGF 600 RF HUTTER). Samples were exposed under conditions listed in Table 1.

\section{Wettability}

Contact angles of water on the different substrates were measured in laboratory atmosphere at room temperature using the sessile drop method of a contact angle goniometer (Dataphysics OCA 20). A drop of $3 \mu \mathrm{l}$ was deposited on the surface of the substrates before and post-treated ones by $\mathrm{CF}_{4}-\mathrm{Ar}$ plasma and each reported angle was calculated on the average of six measurements taken at different points on the sample. The surface energy and its dispersive and polar components were computed according the Owens-WendtRath-Kaeble (OWRK) method (Palamà et al., 2015), also referred to as geometric mean, using water as polar liquid and diiodomethane as apolar liquid, whose surface tensions are reported as in Table 2 . The method assumes that the surface energy, $\gamma \mathrm{s}$, of the solid surface can be calculated from the surface energies of the individual phases, $\gamma_{1}$ and $\gamma_{s}$, as follows: $\gamma_{l}(1+\cos \theta) / \gamma_{l}(1+\cos \theta)=\left(\gamma_{s}^{d} \gamma_{l}^{d}\right)^{1 / 2}+\left(\gamma_{s}^{p} \gamma_{l}^{p}\right)^{1 / 2}$ with $\gamma_{s}^{\mathrm{d}}$ and $\gamma_{s}^{\mathrm{p}}$ being the dispersive and the polar contributions to the surface energy, respectively.

Table1:- Plasma treatments of TEOS and SU-8

\begin{tabular}{|c|c|c|c|c|}
\hline Process & $\begin{array}{c}\text { Gas flow } \\
(\mathrm{sccm})\end{array}$ & $\begin{array}{c}\text { Pressure } \\
(\mathrm{mTorr})\end{array}$ & $\begin{array}{c}\text { RF power } \\
(\mathrm{W})\end{array}$ & $\begin{array}{c}\text { Time } \\
(\mathrm{min})\end{array}$ \\
\hline $\mathrm{CF}_{4}$ & 150 & 40 & 150 & 8,3 \\
\hline $\mathrm{Ar}$ & 100 & 40 & 200 & 3 \\
\hline
\end{tabular}

Table2:- Surface energy and its dispersive and polar components of water and diiodomethane. 32

\begin{tabular}{|l|c|c|c|}
\hline \multirow{2}{*}{ Solution } & \multicolumn{3}{|c|}{ Surface Energy $\left(\mathrm{mJ} / \mathrm{m}^{2}\right)$} \\
\cline { 2 - 4 } & $\gamma_{1}$ & $\gamma_{1}^{\mathrm{d}}$ & $\gamma_{1}^{\mathrm{p}}$ \\
\hline Water & 72.8 & 21.8 & 51.0 \\
\hline Diiodomethane (DI) & 50.8 & 50.4 & 0.4 \\
\hline
\end{tabular}

\section{Characterization}

Morphological characterization of the surfaces before and post plasma treatments has been carried out by Atomic Force Microscopy (AFM) with a Park System XE-100 Advanced Scanning Probe Microscope operating in tapping mode, under ambient conditions and with a standard silicon cantilever. A scan rate of $0.3-1 \mathrm{~Hz}$ at a resolution of $512 \mathrm{pixels} / \mathrm{line}$ was employed. Reported root mean squared area roughness (rms) values are the average of at least three different regions, with the standard deviation of these measures as the uncertainty.

Surface chemical composition and atomic electronic configuration of the substrates was investigated using an Escalab Mk II spectrometer (VG Scientific, UK) equipped with a standard Al K $\alpha$ excitation source and a 5-channeltron detection system. Spectra were collected with an $0.1 \mathrm{eV}$ step at $20 \mathrm{eV}$ constant pass energy, which corresponds to $1.0 \mathrm{eV}$ energy resolution for $\mathrm{Ag}_{3} \mathrm{~d}_{5 / 2}$. The uncertainty of the binding energy (BE) was $\pm 0.1 \mathrm{eV}$ Quantification of the elemental ratios was performed using the CasaXPS software, after subtraction of the Shirley background and using a peak-fitting routine with Voigt functions.

\section{Results and Discussion:-}

Preparation of controlled wetting substrates is based on the combination of surface chemical component (i.e. surface free energy) and geometrical microstructure (i.e. roughness and microposts) (Seemann et al., 
2005; Bixler and Bhushan, 2013). With appropriate pattern geometries and roughness, controlled wetting may allow the liquid to be confined completely. Micropost-structured surfaces with various geometries were constructed lithographically using SU-8 (see Experimental Section). Various geometries of width (d) and spacing (l) among the posts were chosen in order to vary the value of the fill factor values $\left(\varphi_{\mathrm{s}}\right)$, which denote the fraction of the projected area of the solid surface wetted by water, so as to evaluate the latter's influence on the wettability. The height of the microposts was set at $H=25 \mu \mathrm{m}$, while the width and spacing varied, as reported in Table 3 . The fill factor was expressed as $\left(\mathrm{d}^{2}\right) /(\mathrm{d}+1)^{2}$, allowing to obtain correspondingly microposts with various fill factors, whereas a fill factor of a flat sample was obviously 1.

Table3:-Geometric parameters and fill factor of the microstructured post substrates with width $\mathrm{d}$ and spacing 1 .

\begin{tabular}{|c|c|c|}
\hline Sample & width, spacing $(\mu \mathrm{m})$ & fill factor \\
\hline 1 & $\mathrm{~d}=50,1=100$ & 0.11 \\
\hline 2 & $\mathrm{~d}=40,1=40$ & 0.25 \\
\hline 3 & $\mathrm{~d}=42,1=28$ & 0.36 \\
\hline 4 & $\mathrm{~d}=47,1=16$ & 0.55 \\
\hline 5 & flat & 1 \\
\hline
\end{tabular}

Activation of the substrates was performed by first exposing to a $\mathrm{CF}_{4}$ plasma followed by an $\mathrm{Ar}$ plasma to ensure the formation of reactive radicals on the surface. A schematic of the grafting process is shown (Fig 1). As illustrated, exposure of the $\mathrm{Si}-\mathrm{OR}$ groups of $\mathrm{SU}-8 / \mathrm{TEOS}$ to $\mathrm{CF}_{4}$ and $\mathrm{Ar}$ plasma, generated $\mathrm{Si}-\mathrm{OH}$ groups, which formed covalent bonds on the solid surface through condensation reactions and opening the epoxy rings of the SU-8.

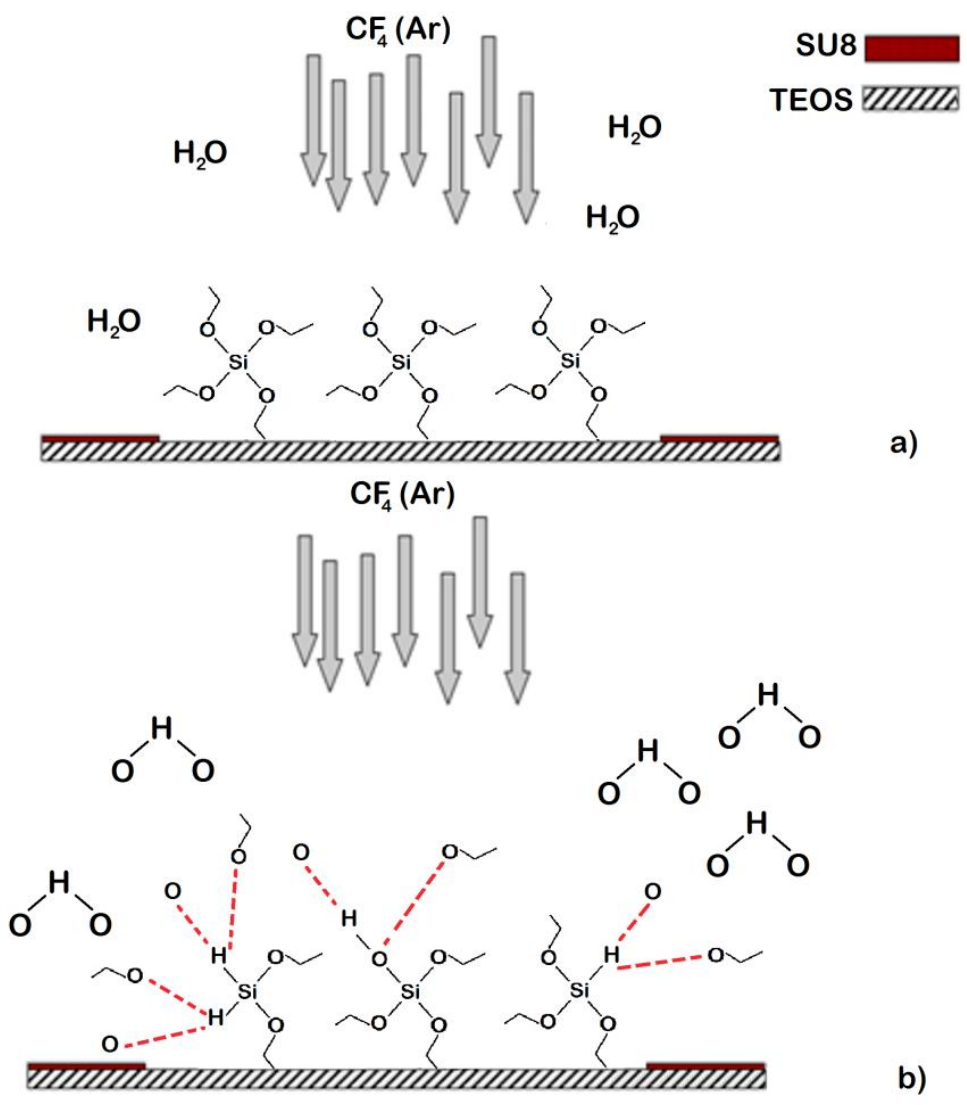

Fig 1:-Schematic representation of the chemical reactions which take place during plasma irradiation: a) TEOS with SU-8 lithography under CF4 (Ar) flow; b) Formation of O-H group linked to TEOS surface. Red dashed lines represent broken links. 
In fact the $\mathrm{CF}_{4}$ plasma inside the RIE chamber can trigger, due to its high energy, a reaction between the substrate surface molecules and the vapour aqueous molecules present inside the vacuum chamber. Therefore, $\mathrm{O}-\mathrm{H}$ groups were formed (linked to silicon instead of $\mathrm{O}-\mathrm{CH}_{2}-\mathrm{CH}_{3}$ groups), leading to a high hydrophilic surface. Also groups like $\mathrm{Si}-\mathrm{OH}$ and $\mathrm{C}-\mathrm{O}$ were reported to be incorporated into the film bulk when TEOS was employed as a substrate (Aydil, 1996). This was confirmed by XPS analysis carried out on the untreated and plasma irradiated micropost-structured SU-8/TEOS surfaces. Full scans (Fig 2), were acquired in order to determine the elemental surface composition of various elements present and high resolution $\mathrm{C} 1 \mathrm{~s}$ scans were acquired to study the chemical species of carbon. For the untreated SU-8 substrate, the surface chemical composition was characterized by the presence of oxygen and carbon, as expected from an aromatic polyether such as SU-8. The peak-fitting analysis of the C1s spectrum scans of the untreated surfaces, showed two components positioned at $\mathrm{BE}=285.0 \mathrm{eV}$ and $286.8 \mathrm{eV}$, which were assigned to the presence of aliphatic and aromatic carbon $(\mathrm{C}-\mathrm{C}, \mathrm{C}=\mathrm{C}, \mathrm{C}-\mathrm{H})$ and ether carbon $(\mathrm{C}=\mathrm{O})$, respectively. The presence of aromatic compounds was confirmed by the presence of $\square-\square *$ shakeup satellite positioned at BE $=291.3 \mathrm{eV}$ and carbonates (Fig 2 and Table S1-S2), (Kastenmeier et al., 1999; Jeong et al., 2003; Seemann et al., 2005). Exposure to the inert Ar plasma causes structural and chemical changes to the surface with an enrichment of $\mathrm{C}=\mathrm{O}$ and $\mathrm{COO}$ groups on $\mathrm{SU}-8$ and breakage of the O-H and $\mathrm{C}-\mathrm{H}$ bonds (Zhang et al., 2005). After plasma treatment, on the SU-8 surface, the amount of carbon-oxygen containing groups $(\mathrm{C}=\mathrm{O}$ and $-\mathrm{COO})$ were reduced whereas the aliphatic $\mathrm{C}-\mathrm{C}$ groups slightly increased and the aromatic shakeup peak disappeared. In addition, the O1s spectra revealed new peaks at 530.9 and 533.4 $\mathrm{eV}$, corresponding to $\mathrm{C}=\mathrm{O}$ groups and $\mathrm{H}_{2} \mathrm{O}$, which were not observed for the untreated $\mathrm{SU}-8$ surfaces. The increase in the peak area ratio of oxygen to carbon on the SU-8 surface from 1.04 to 1.18 reflects an augmented oxidation whereas the TEOS substrate showed a decrease peak area ratio of oxygen to carbon as compared with the elemental composition of the original surface (Table S1-S2). This was interrelated to the opening of the epoxy groups, which reacted with the oxygen present in the environment, forming hydrophilic $-\mathrm{OH}$ groups on the surface. In addition, the increase in full width at half maximum (FWHM) of the oxygen peak is a hint for different oxygen species present in the oxidized TEOS film. This is most probably due to a mixture of ether, aldehyde, and carboxylic acid functions. The small nitrogen signal might result from an imperfect oxygen atmosphere during the plasma process. 


\section{SU-8}
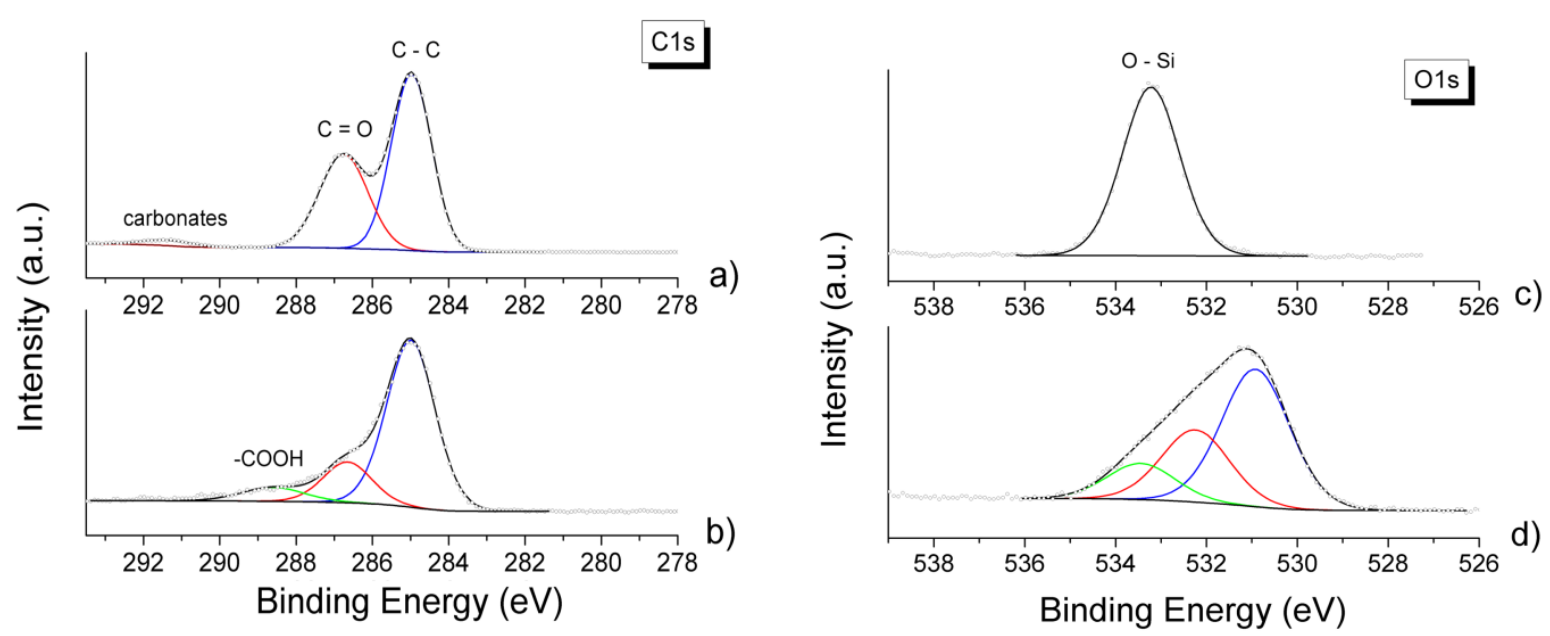

\section{TEOS}
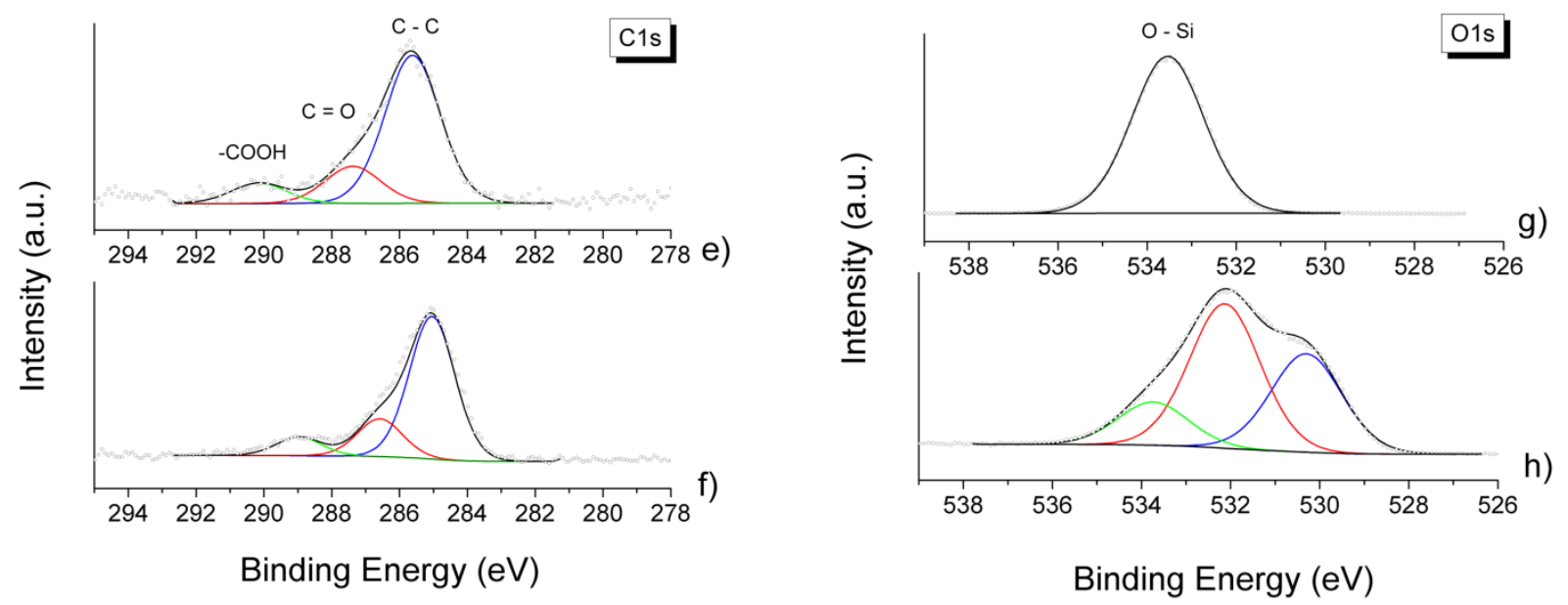

Fig 2:-XPS high-resolution C1s scan of (a) untreated SU-8 (b) plasma irradiated SU-8; XPS high-resolution O1s scan of (c) SU-8 (d) plasma irradiated SU-8; XPS high-resolution C1s scan of (e) untreated TEOS (f) plasma irradiated TEOS; XPS high-resolution O1s scan of (g) untreated TEOS $(\mathrm{h})$ plasma irradiated TEOS.

AFM studies on both untreated and plasma irradiated SU-8 and TEOS surfaces were investigated, (Fig 3). Untreated SU-8 and TEOS samples revealed a smooth uniform topography of the surfaces with arms of 0.9 $\pm 0.3 \mathrm{~nm}$ and $0.52 \pm 0.02 \mathrm{~nm}$ respectively. After plasma treatment substrates presented arms of $12.4 \pm 0.1$ $\mathrm{nm}$ and $0.48 \pm 0.01 \mathrm{~nm}$ respectively and a total height variation of only $20 \mathrm{~nm}$ and $1 \mathrm{~nm}$ respectively. 

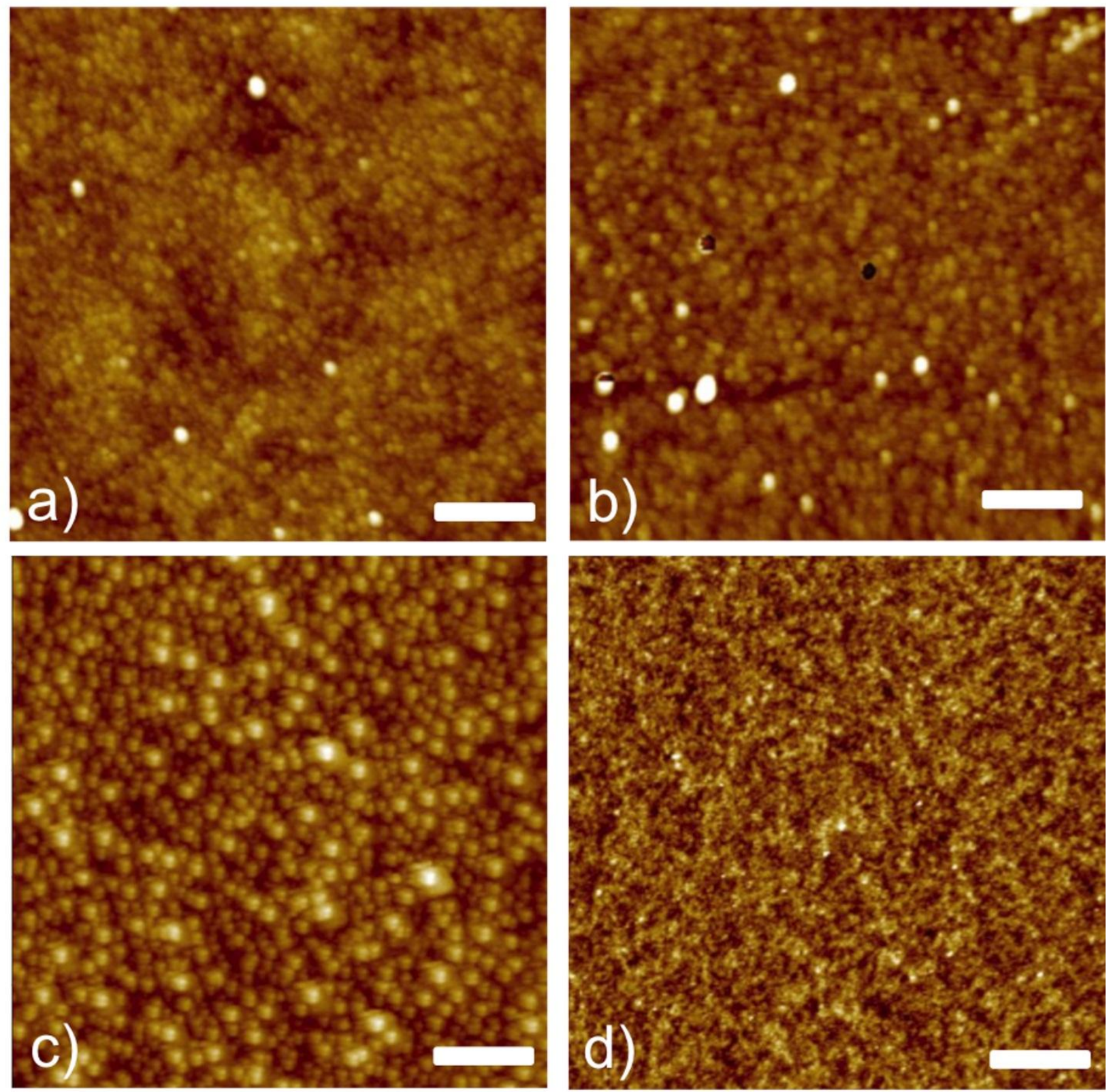

Fig 3:-AFM scans of (a) SU-8 (b) TEOS substrate without plasma irradiation and c) plasma irradiated SU8 ; (d) plasma irradiated TEOS substrate. Scale bar $1 \mu \mathrm{m}$.

It is therefore reasonable to assume that the plasma irradiation on the surface topography of the TEOS substrate has little to no effect on the topography of the substrate. Therefore the interplay between surface topography and wettability on the TEOS surface depends mainly from the chemical changes. The surface morphology of the SU-8 plasma treated surfaces showed a somewhat dense network of macroscopic chains. From the AFM scans, we can infer that the SU-8 is etched due to $\mathrm{CF}_{4}$ radicals and the bonding structure induced a rearrangement of the chemical bonds forming carbon-rich functional groups when the $\mathrm{CF}_{4}$ plasma treatment is applied. This means that the roughening with $\mathrm{Ar}+\mathrm{CF}_{4}$ plasma not only reduces the stable oxide layer on the surface but also easily modifies the surface for sufficient wettability because of the chemical activation on the surface. 
Contact angle measurements of deionized water droplets on untreated and plasma irradiated SU-8 micropost-structured surfaces were used to characterize the wettability nature of the surface. Untreated TEOS and SU-8, were found to show weak hydrophilicity/hydrophobicity, exhibiting a contact angle of respectively $68^{\circ}$ and $80^{\circ}$. After plasma irradiation, an interesting sharp transition from hydrophobicity to hydrophilicity of the SU-8 and TEOS substrates was observed (Fig 4). Water droplets placed on the plasma irradiated SU-8 flat and micropost-structured surfaces spontaneously spread to a near-zero contact angle (Fig 4), whereas the water contact angle of TEOS substrates decreased to approximately $29^{\circ}$.

- without Plasma Irradiation

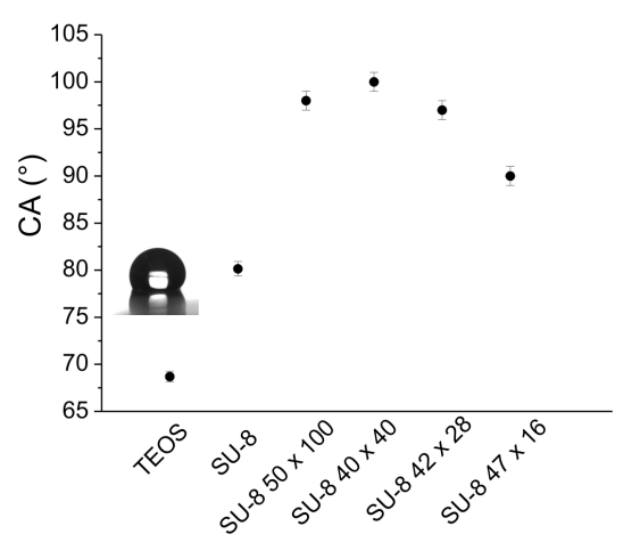

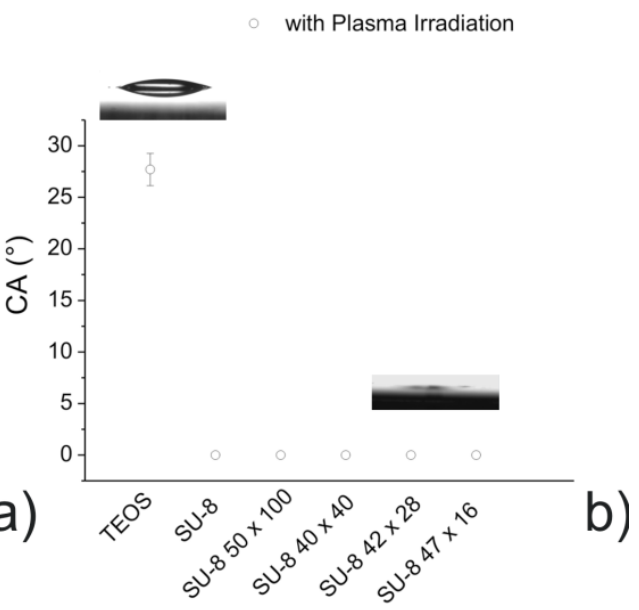

Fig 4:-Static water in air (a-b) of TEOS and SU-8 flat and micropatterned surfaces of various post square dimensions and pitch distance ( $\mathrm{d} \times \mathrm{l}$ ) with (a) and without plasma irradiation (b) in air, enclosed with the corresponding water droplet shape.

This phenomenon has been described by the classical Wenzel equation, which predicts how roughness enhances the wettability of a smooth hydrophilic surface as a result of the reduction in the surface energy of the system (Wenzel, 1936; Zheng et al., 2004; Quéré, 2008). In other words, increasing the roughness enhances the hydrophilicity of the substrate surface. In the case of superhydrophilic or superwetting surfaces, an additional model has to be considered: the "hemi-wicking" or composite-drop model (Quéré, 2002), where the liquid drop is assumed to be sitting on a composite surface made of solid and liquid. According to this model the CA of the liquid drop will reduce with the roughness ratio. This was in agreement with the TEOS substrates, but not for the SU-8. The increase in superhydrophilicity of the SU-8 substrates observed in this study may be explained as follows. First, superhydrophilicity may have been enhanced by the larger surface area created by $\mathrm{CF}_{4}$ etching. Second, the Argon treatment may have served to clean the surface, decreasing the likelihood of hydrocarbon being absorbed during storage in air. The resulting increase in surface area appears to have enhanced the hydrophilicity of the surface.

To understand these different wetting morphologies in a systematic and quantitative way we applied the basic wetting theories that outline the guidelines for the study of the wetting characteristics of droplets (Wenzel, 1936; Quéré, 2002). The Wenzel model describes a sticky state where a drop of liquid fully penetrates the asperities of the surface, associated to the contact line pinning expressed as (Wenzel, 1936):

$$
\cos \theta_{\mathrm{W}}=\mathrm{r}_{\mathrm{f}} \cos \theta_{\mathrm{Y}}
$$

where $\theta_{\mathrm{Y}}$ is the intrinsic water CA on the corresponding smooth surface and $\mathrm{r}_{\mathrm{f}}$ is the surface roughness of the wetted area (Cassie and Baxter, 1944). Whereas, the Cassie Baxter model, describes a slippery state, where the liquid drop is suspended by the formation of air pockets on the top of the asperities, hence to a depinning from the surface (Quéré, 2002). In the Cassie regime, a liquid droplet on a surface can be described by Eqn 2 (Lafuma and Quere, 2003; Marmur, 2003; Michielsen and Lee, 2007):

$$
\cos \theta_{\mathrm{CB}}=\varphi_{\mathrm{s}} \cos \theta_{\mathrm{Y}}+\varphi_{\mathrm{s}}-1
$$


where $\mathrm{d}$ is the base dimension of the square post, 1 is their center-to-center pitch, and $\mathrm{H}$ is the post height.

Fig 5:-Plot of the WCA angles of a $3 \mu \mathrm{L}$ drop of water on the untreated SU-8 micropost-structured (a) and
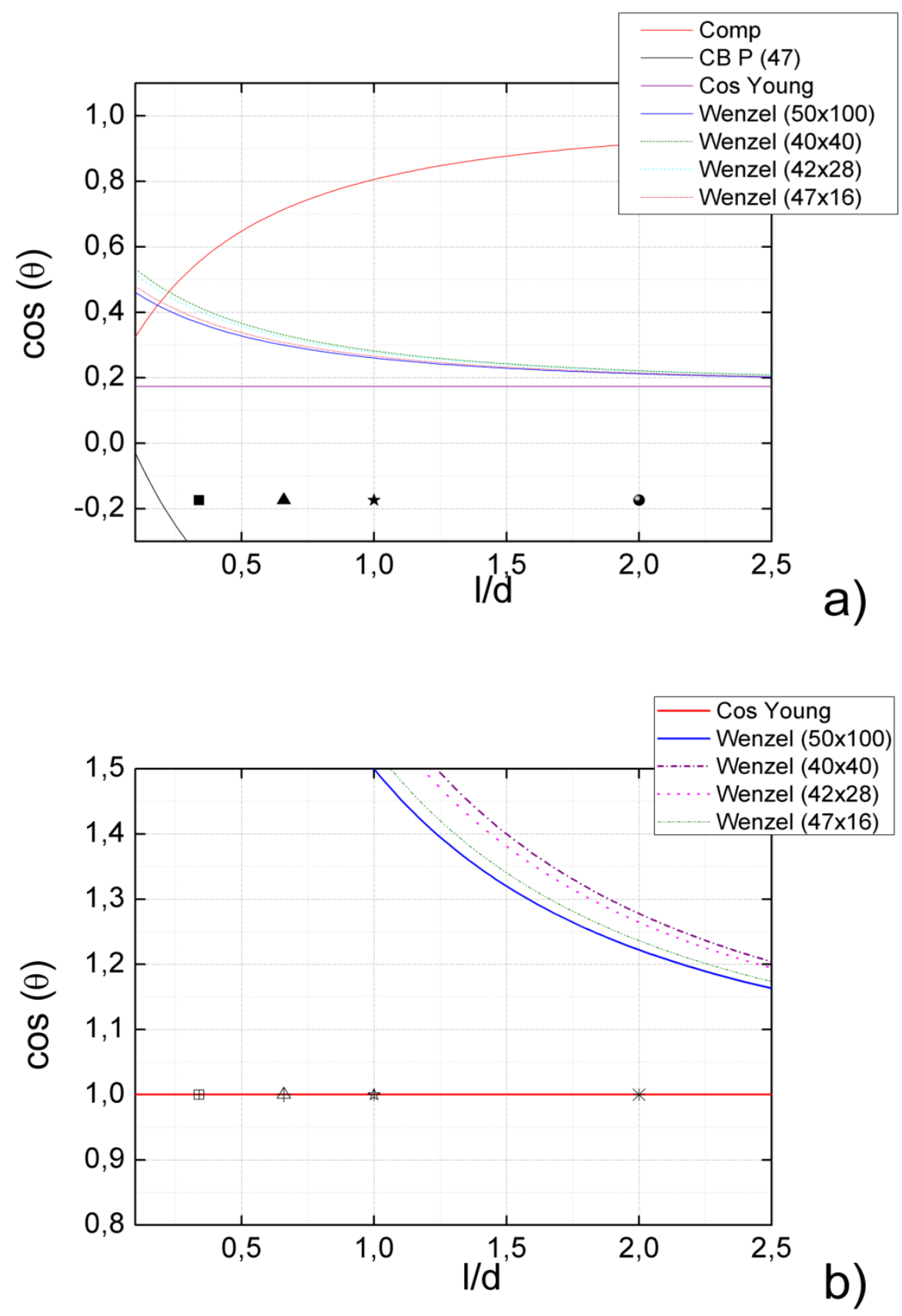

with plasma irradiation (b) as a function of structure geometry. Composite drop (comp-) and Wenzel (W-) curves for square posts are plotted. Individual points indicate experimental data: (square) Posts 50x100 (d x 1); (triangle) Posts 40x40 (d x 1); (star) Posts 42×28 (d x 1); (circle) Posts 47x16 (d x l).

Theoretically, the Wenzel state is more favourable for low-roughness surfaces. For a superwetting substrate, with $\theta_{\mathrm{W}}=0^{\circ}$, the hemi-wicking condition expressed as $\varphi_{\mathrm{s}}=\left(1-\cos \theta_{\mathrm{W}}\right) / 1-\cos \theta_{\mathrm{Y}}$ becomes $\varphi_{\mathrm{s}}>0$, which indicates that the hemi-wicked state will be more stable than the Wenzel state. The Cassie-Baxter 
state, instead, will be more favourable on patterned surfaces with a high roughness where $r>\left(\varphi_{s}-\right.$ $1) / \cos \left(\theta_{Y}\right)+\varphi_{s}$. Reduction of the solid fraction, would improve the hydrophobicity of the substrate (Fig $\mathrm{S} 1$ ), in agreement with the water CA measured values. The experimental WCA along with the theoretical curves were plotted (Fig 5). Because the substrate is weakly hydrophilic, the Wenzel and composite-drop curves were plotted along with the Cassie Baxter curve and Young's angle, which was taken as the angle measured on the flat control. The experimental WCA of micropatterned samples were in agreement with previous reports which demonstrated that roughness can also lead to a superhydrophobic contact angle on a hydrophilic substrate (Herminghaus, 2000; Erbil and Cansoy, 2009). These results suggests that air is trapped among the pillars and indicate a metastable state, since all the composite-drop and Wenzel curves in this case correspond to a lower energy configuration. On the other hand (Fig 5 b) shows that the compositedrop formula is in excellent agreement with the experimental values due to the circumstance that the composite-drop relation does not depend on the aspect ratio of the features.

The stability of the wetting states can be predicted theoretically by comparing the surface energies. The surface energy of the untreated TEOS and SU-8 substrates are reported (Fig 6).

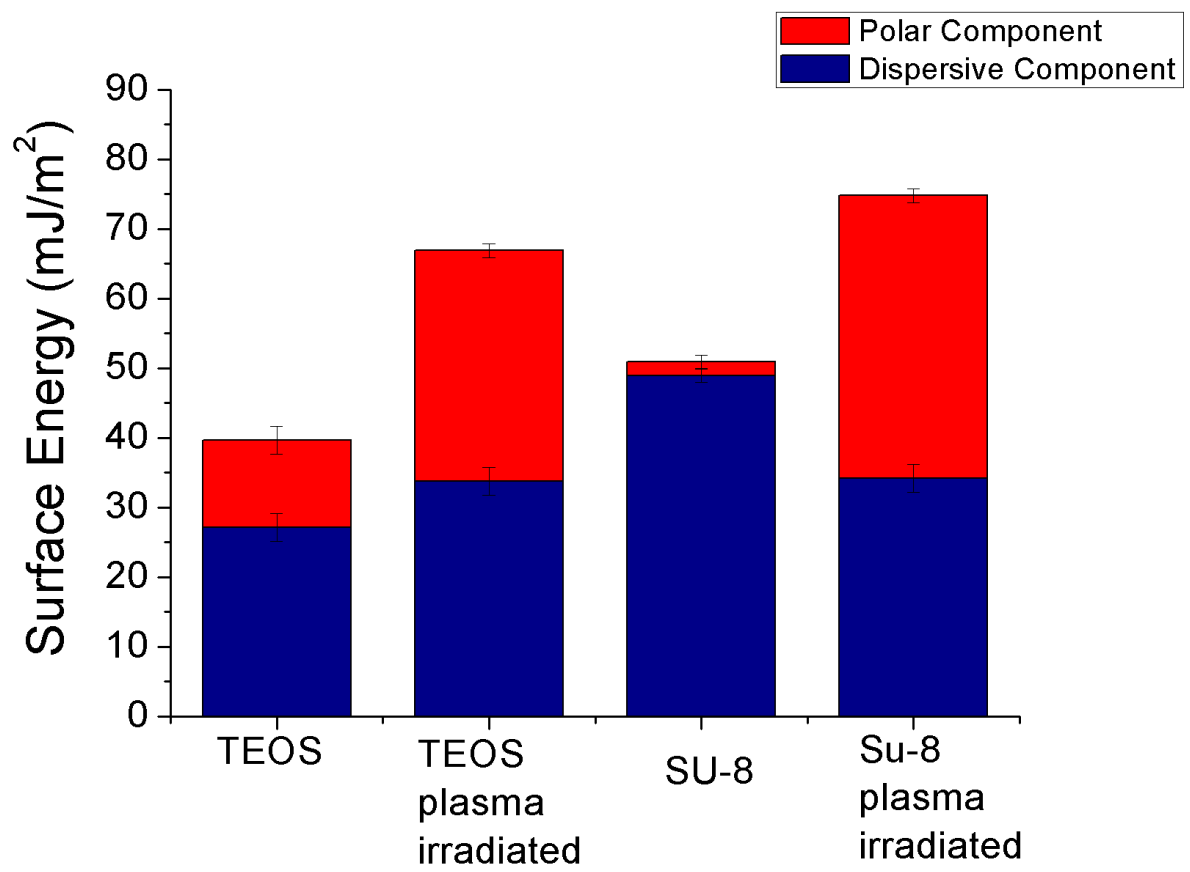

Fig 6:-Polar and dispersive components of the surface energy for TEOS and SU-8 substrates, with polar and dispersive components, before and after plasma treatment. The polar and dispersive components of the surface energy were calculated according the Owens-Wendt theory.

It is evident that the surface energies of both plasma-treated substrates was substantially increased, especially in the polar component $(\gamma p)$ which describes the hydrophilic character of the surface whereas the dispersion component $\left(\gamma_{\mathrm{d}}\right)$ which is related to the hydrophobic character of the surface, was nearly similar among the surface treated substrates. A higher $\gamma_{p}$ leads to higher interaction energy and is interrelated to the surface's increased affinity for the fluid due to an increase in dipole-dipole and hydrogen bonding between the surface and the liquid. Dispersion forces (Lifshitz-Van der Waals interactions), instead, depend on noncovalent and non-electrostatic molecular interactions between the non-polar molecules. The change in the dispersive component of the surface is due to the presence of high surface energy oxygen-containing functional groups on the surface introduced after plasma treatment. Also it is evident that the SU-8 irradiated sample is more wettable related to the higher total surface energy when compared to the TEOS irradiated substrate.

Underwater superoleophobic surfaces generally should comply to two basic design criteria which dispose that when submerged in water 1) the microstructures should be effortlessly filled by the water without 
trapping air pockets, and 2) the oil drop in the underwater condition must remain suspended by the microstructures without seeping into the texture and replacing the trapped water liquid film.. We pre viously pointed out that roughness with dual length scales is necessary for superoleophobicity both in air and underwater (Nishimoto and Bhushan, 2013; Sobiesierski et al., 2015). When immediately immersed in water, the untreated SU-8 and TEOS substrates showed a weak oleophilic behaviour whereas the plasma irradiated showed superoleophobicity with a hogh sliding angle of the oil drop (Fig 7). This was explained considering that the SU-8 irradiated surface was superhydrophilic in air, thus implicating that water molecules rapidly filled the slits, openings and roughness of the constructed rough structures, surrounding the surface completely. Hence, once placed the oil droplet on the substrate underwater, the oil droplet is upheld by the micropatterned structures, with water below the oil droplet, preventing the formation of air pockets and precluding the oil droplet from contacting the substrate. Therefore, this complies with the design criteria and, in the underwater oil-water-solid three-phase regime, the Cassie-Baxter state is formed with oil contact angle larger than $150^{\circ}$.
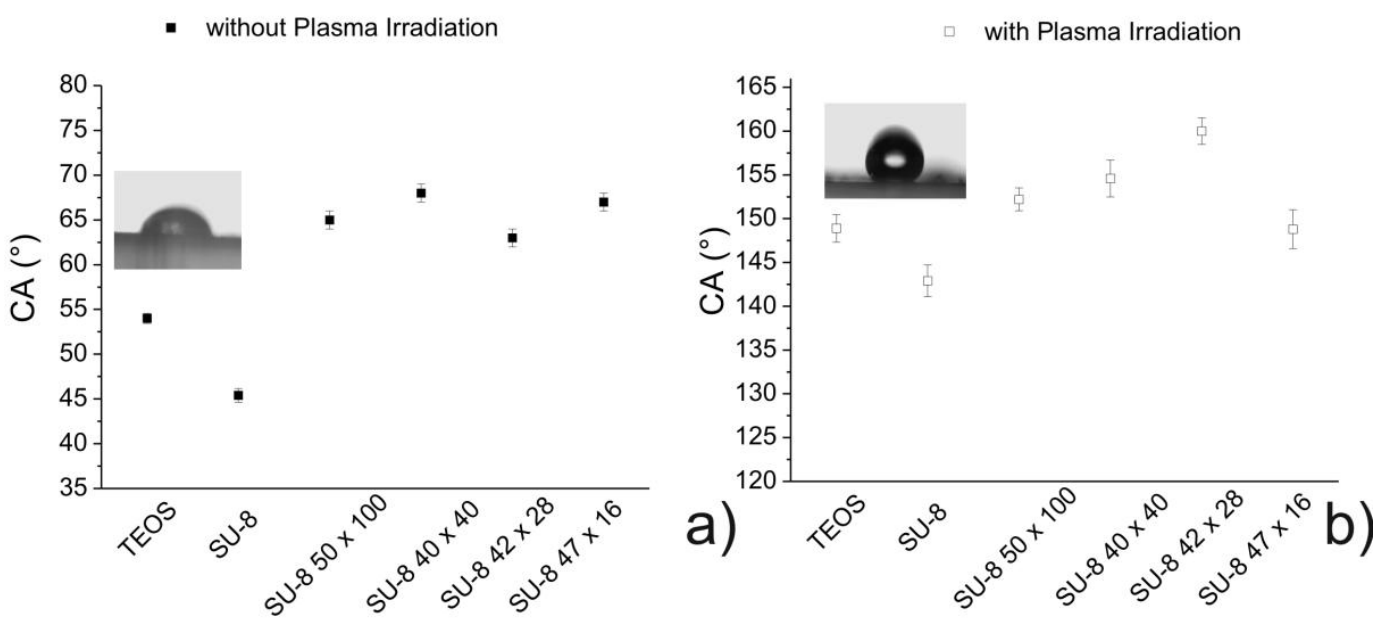

Fig 7:-Underwater oil contact angles of TEOS and SU-8 flat and micropatterned surfaces of various post square dimensions and pitch distance ( $\mathrm{d} \times \mathrm{l}$ ) with (a) and without plasma irradiation (b), enclosed with the corresponding water droplet shape.

Considering Wenzel and Cassie's equations expressed as a function of the CAs of oil in water, oil in air, and water in air, $\theta_{\mathrm{OW}} \theta_{\mathrm{O}}$ and $\theta_{\mathrm{W}}$, respectively, the experimental OCAs along with the theoretical predictions were plotted (Fig 8). To achieve an underwater oleophobic surface, $\cos \theta_{\mathrm{Ow}}$ should be negative, according to Eqn (1). As a result, $\cos \theta_{\mathrm{Ow}}=-0.85$ and -0.79 for the flat TEOS and SU-8 plasma irradiated samples, in agreement with the theoretical considerations and both substrates behaved as an underwater oleophobic surface. The experimental values of the OCA on the micropost irradiated surfaces (Fig 8b) were also in agreement with the Cassie Baxter curve, because the Cassie-Baxter curve is always at a higher energy than the Wenzel one, that is, $\cos \theta_{\mathrm{CB}}>\cos \theta_{\mathrm{W}}$. However, the Cassie-Baxter regime is stabilized only for $1 / \mathrm{d}<1.8$ (50x100), $1 / \mathrm{d}<1.7(40 \times 40), 1 / \mathrm{d}<1.72(42 \times 28)$ and $1 / \mathrm{d}<1.78(47 \times 16)$, which are the critical values at which the corresponding Wenzel angles become unattainable $\left(\cos \theta_{\mathrm{W}}<-1\right)$. 
Fig 8:-Plot of the underwater OCA angles on the untreated SU-8 micropost-structured (a) and with plasma irradiation (b) as a function of structure geometry (l. Composite drop (comp-) Cassie Baxter and Wenzel curves for square pillars are plotted. Individual points indicate experimental data: (square) Posts 50x100 (d x 1); (triangle) Posts 40x40 (d x 1); (star) Posts 42x28 (d x 1); (circle) Posts 47x16 (d x 1).
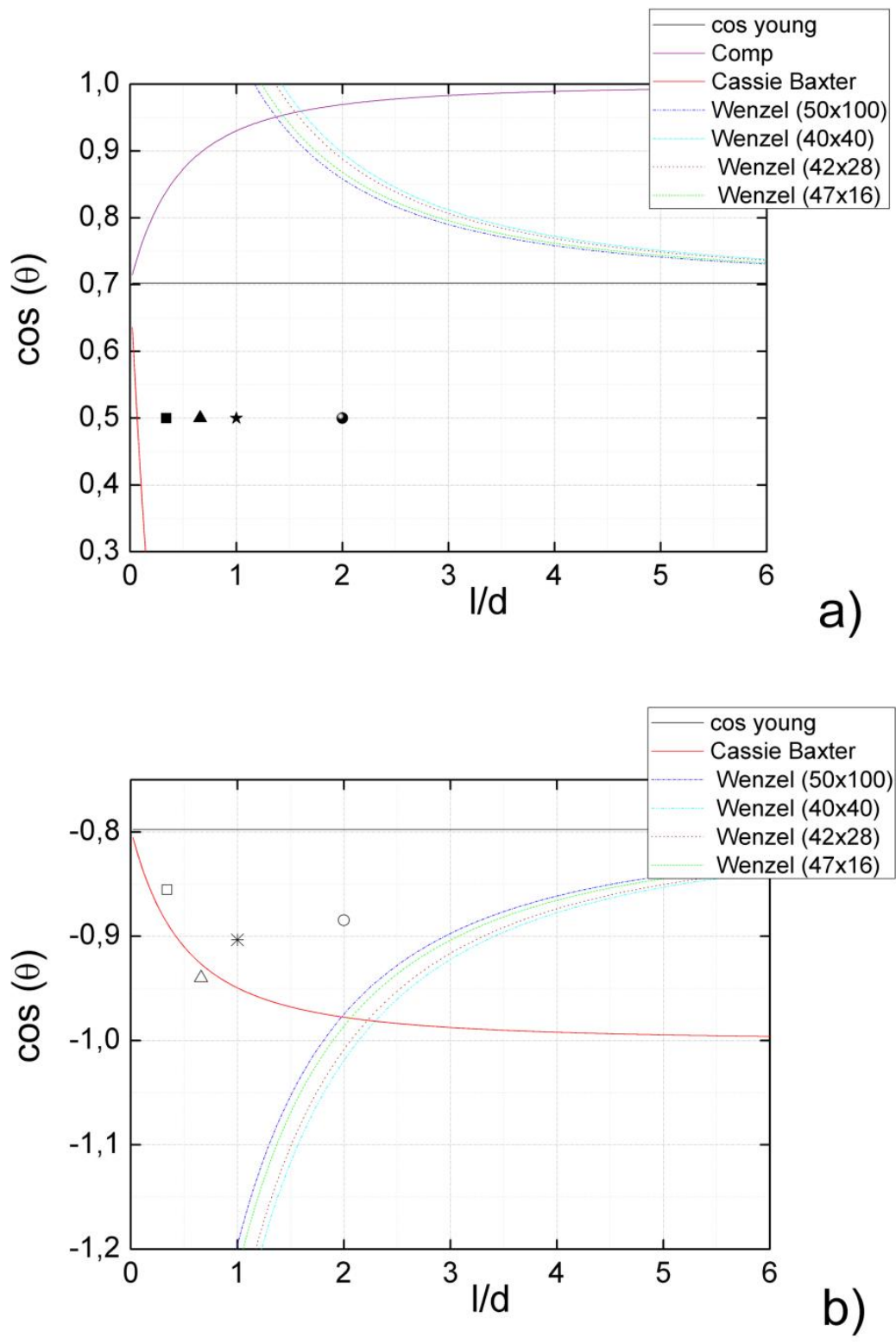

According to Cassie's equation (Eqn 2) the smaller the solid fraction, the better the oleophobic ability. Given that $\square_{\mathrm{s}}$ is 0.11 for pillars $50 \times 100,0,25$ for pillars $40 \times 40,0,36$ for pillars $42 \times 28$, and 0,55 for pillars 47x 16, the measured values for the underwater oil CA (reported in Fig S1) were higher for the smaller the solid fraction, agreeing well with the theoretical predictions.

For a micropost structured surface, the condition that agrees with the water filling criterion can be expressed by the equation $\theta_{\mathrm{Y}}<\theta_{\mathrm{c}}=\max [\square, \arctan (1 / 2 \mathrm{H})]$ where $\square$ is the local geometric angle at the upper corner of posts $\left(90^{\circ}\right.$ for vertical posts), 1 the pitch, and $\mathrm{H}$ the post height and $\theta \mathrm{c}$ is the maximum value between the two. ${ }^{52}$ The condition that considers the suspension of the oil drop on the microposts requires that the underwater intrinsic oil CA $\theta_{\mathrm{oW}}>\square$. This was confirmed by our experimental values for the micropost 
irradiated structured surfaces where the oil CA underwater $\theta_{\mathrm{ow}}$ was $142,9^{\circ}$ while without plasma treatment this was not satisfied as the $\theta_{\text {ow }}$ was $45,4^{\circ}$. With reference to the surface chemistry prediction that meets these criteria we applied the relationship between $\theta \mathrm{o}$ and $\theta \mathrm{w}$ expressed as $\theta_{\mathrm{OW}}=180^{\circ}-\arccos \left\{\left(2\left(\cos \theta_{\mathrm{Y}}-1\right) /\left[\left(\gamma_{\mathrm{O}}-\gamma_{\mathrm{OW}}\right) / \gamma_{\mathrm{W}}\right]+1\right\}>\phi\right.$. Using diiodomethane we considered that $\gamma_{\mathrm{w}}=72.8, \gamma_{\mathrm{O}}=50.8$ and $\gamma_{\mathrm{OW}}=35,86 \mathrm{mN}^{*} \mathrm{~m}^{-1}$, the micropost irradiated structured surfaces showed to fulfill the requirement for establishing the solid-oil-water composite interfaces. Thus complicated geometries such as a re-entrant (i.e., local negative slope) texture of the post were not necessary in our case to obtain underwater superoleophobicity.

The key motivation for this underwater behaviour was explained by considering the high amount of water trapped by the microstructure of the surface due to its inherent hydrophilicity which in turn reduced the contact area between the oil and the surface, as previously reported (Feng et al., 2004).

As proof of concept for water confinement, different geometries were fabricated, square and cylindrical posts and a honeycomb structure (Fig 9). The SU-8 walls acted as barriers by confining the water droplets inside the geometries and preventing unwanted spreading. The hydrophilic TEOS surface strongly anchored the water to form a uniform film.
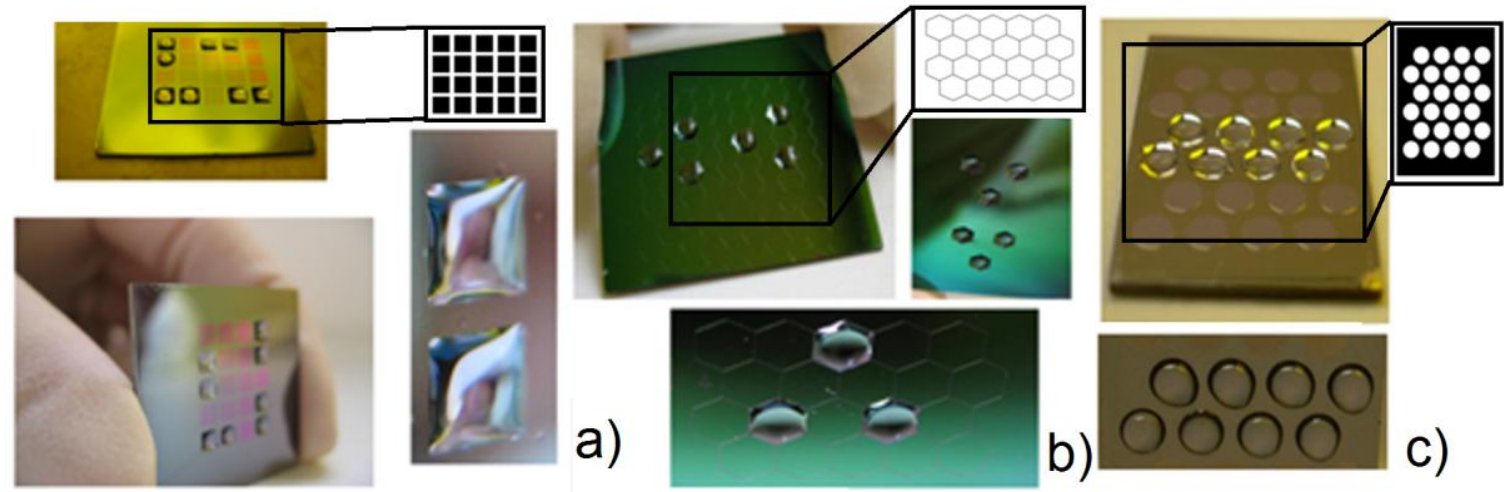

Fig 9:-Water drops confined on SU-8 micro patterned plasma irradiated substrates with different geometries a) square b) honeycomb and c) circle, showing the successfulness of water confinement.

The long term stability of the wettability interrelated to surface activation is another important aspect for the practical use of the water confinement. The stability of the treatment was assessed by surface wettability over a period of seven months. During this aging period the micropost samples were kept in a glass vial, specifically at dry storage at $25{ }^{\circ} \mathrm{C}$. Within the first weeks, the surface energy and contact angle almost remained unvaried. Over a couple of months, samples completely recovered their contact angles to their native values, due to hydrophobic recovery, generally the main disadvantage of plasma irradiated substrates.

\section{Conclusions:-}

In conclusion, in the context of droplet microfluidics, wettability is very important to control the water movement at the microscale. Our key result here is the formation of a highly controlled wettable SU-8 pattern on the TEOS substrates using a single step plasma treatment. We found that the CF4/Ar plasma treatment along with the three-dimensional control of the topography, led to complete liquid confinement on the surface of the pattern. Such technique allowed to obtain hydrophilic wells, selectively converting hydrophobic areas to superhydrophilic ones in a single step process and preventing any wetting beyond the lithographically prepared features. With appropriate pattern geometries, controlled wetting allowed the liquid to be confined completely. Moreover similarly to sharkskin, the plasma irradiated microposts demonstrated underwater superoleophobicity. This was due to a hydrophilic behaviour of the irradiated plasma microposts that would rather interact with water than oil. Additionally, by tuning the post dimension of the plasma irradiated microposts to reduce the solid fraction, the underwater oleophobicity could be increased, thus reducing the complexity of the geometry of the structures. The effect of plasma was 
investigated on the wetting behaviour by water and oil contact angles in air and underwater. The change in wetting properties gives importance of surface chemistry, roughness and solid fraction. The effects of plasma treatment on the substrates differed slightly endowing SU-8 with a slightly rougher substrate whereas the silicon appeared smoother than the surface of the untreated samples. Therefore the surface chemistry was found to be responsible for the changes in the wettability of the substrates since (1) there was no substantial change in the morphology and roughness of the substrate, and (2) there was an increased presence of oxidants on the SU-8 substrate of the XPS spectra of the treated SU-8 from the untreated SU-8. XPS analysis, in fact, indicated a change in the surface chemical property through inclusion of atmospheric oxygen, hence creating hydrophilic groups on the surface. The irradiated samples displayed predominantly a composite-drop behaviour in air whereas a Cassie Baxter state underwater. We expect this method to have a wide variety of applications ranging from microfluidics to underwater appliances. Such structures are, in fact, especially beneficial in applications where one only needs to have a patterned hydrophilic surface (i.e. in display fabrication of polymer electronic devices where polymers are ink-jet printed onto pre-patterned surfaces) or underwater oil gradient wettability. Using SU-8 as a coating can greatly advance the oil-water separation methods, encouraging various practical applications and effective results of emergent environmental issues.

\section{Acknowledgements:-}

This work was supported by the Italian Association for Cancer Research (AIRC) through the grant MFAG n. 16803, and Tecnomed(Progetto FISR - C.N.R.: "Tecnopolo di Nanotecnologia e Fotonica per la Medicina di Precisione" - CUP B83B17000010001). We are grateful to Dr. A. Zocco for useful discussion and technical support. We would like to thank Mr Rand Jean for collecting the XPS data and for his help in analyzing the XPS data.

\section{Supporting Information:-}

Table S1:-Parameters showing binding energy (eV), chemical bonds, FWHM (eV), total area (eV) and relative percentage concentration of spectral components of untreated SU-8/TEOS substrates.

\begin{tabular}{|c|c|c|c|c|c|}
\hline \multicolumn{6}{|c|}{ TEOS } \\
\hline Name & Peak BE & FWHM eV & Area (P) CPS.eV & Atomic $\%$ & Bond \\
\hline C1s - 1 & 285.0 & 1.92 & 2162.81 & 3.6 & $\mathrm{C}-\mathrm{C}$ \\
\hline C1s - 2 & 286.8 & 1.92 & 541.81 & 0.9 & $\mathrm{C}=\mathrm{O}$ \\
\hline C1s - 3 & 289.6 & 1.92 & 297.61 & 0.5 & $-\mathrm{COO}$ \\
\hline O1s - 1 & 532.9 & 1.92 & 70814.48 & 41.6 & $\mathrm{Si}-\mathrm{O}$ \\
\hline Si2p3 & 103.6 & 1.88 & 8755.43 & 26.7 & $\mathrm{Si}-\mathrm{O}$ \\
\hline \multicolumn{6}{|c|}{ TEOS + SU-8 } \\
\hline Name & Peak BE & FWHM eV & Area (P) CPS.eV & Atomic $\%$ & Bond \\
\hline C1s - 1 & 285.0 & 1.24 & 19690.68 & 48.4 & $\mathrm{C}-\mathrm{C}$ \\
\hline C1s - 2 & 286.8 & 1.49 & 12589.24 & 31.0 & $\mathrm{C}=\mathrm{O}$ \\
\hline C1s - 3 & 291.4 & 1.58 & 776.00 & & $\square-\square^{*}$ shake-up satellite \\
\hline F1s & 686.2 & 1.56 & 1259.83 & 0.7 & $\mathrm{C}-\mathrm{F}$ \\
\hline O1s & 533.2 & 1.49 & 20577.72 & 17.8 & $\mathrm{Si}-\mathrm{O}$ \\
\hline Si2p3 & 102.4 & 1.49 & 454.65 & 2.0 & $\mathrm{Si}-\mathrm{O}$ \\
\hline
\end{tabular}

Table S2:-Parameters showing binding energy (eV), chemical bonds, FWHM (eV), total area (eV) and relative percentage concentration of spectral components of plasma irradiated SU-8/TEOS substrates.

\begin{tabular}{|c|c|c|c|c|c|}
\hline \multicolumn{6}{|c|}{ TEOS after RIE } \\
\hline Name & Peak BE & FWHM eV & Area (P) CPS.eV & Atomic $\%$ & Bond \\
\hline C1s -1 & 285.0 & 1.74 & 6919.95 & 11.7 & $\mathrm{C}-\mathrm{C}$ \\
\hline C1s -2 & 286.6 & 1.74 & 1831.41 & 3.1 & $\mathrm{C}=\mathrm{O}$ \\
\hline $\mathrm{C} 1 \mathrm{~s}-3$ & 289.0 & 1.74 & 915.55 & 1.6 & $-\mathrm{COO}$ \\
\hline $\mathrm{F} 1 \mathrm{~s}-1$ & 684.4 & 2.16 & 3412.27 & 1.4 & Fluorides \\
\hline
\end{tabular}




\begin{tabular}{|c|c|c|c|c|c|}
\hline F1s -2 & 686.7 & 2.16 & 1761.80 & 0.7 & $\mathrm{C}-\mathrm{F}$ \\
\hline $\mathrm{O} 1 \mathrm{~s}-1$ & 530.3 & 1.88 & 33792.16 & 20.1 & $\mathrm{C}=\mathrm{O}$ \\
\hline $\mathrm{O} 1 \mathrm{~s}-2$ & 532.1 & 1.88 & 49537.07 & 29.5 & $\mathrm{Si}-\mathrm{O}$ \\
\hline $\mathrm{O} 1 \mathrm{~s}-3$ & 533.7 & 1.88 & 14803.84 & 8.8 & $\mathrm{H} 2 \mathrm{O}$ \\
\hline Si2p3 & 103.0 & 2.19 & 7309.07 & 22.6 & $\mathrm{Si}-\mathrm{O}$ \\
\hline \multicolumn{6}{|c|}{ TEOS + SU-8 after RIE } \\
\hline Name & Peak BE & FWHM eV & Area (P) CPS.eV & Atomic \% & Bond \\
\hline $\mathrm{C} 1 \mathrm{~s}-1$ & 285.0 & 1.49 & 8404.51 & 44.4 & $\mathrm{C}-\mathrm{C}$ \\
\hline $\mathrm{C} 1 \mathrm{~s}-2$ & 286.7 & 1.49 & 2050.43 & 10.8 & $\mathrm{C}=\mathrm{O}$ \\
\hline $\mathrm{C} 1 \mathrm{~s}-3$ & 288.6 & 1.92 & 911.19 & 4.8 & $-\mathrm{COO}$ \\
\hline F1s & 684.8 & 1.98 & 2273.29 & 2.9 & Fluorides \\
\hline N1s & 399.7 & 2.34 & 808.78 & 2.4 & \\
\hline $\mathrm{O} 1 \mathrm{~s}-1$ & 530.9 & 1.77 & 9967.52 & 18.5 & $\mathrm{C}=\mathrm{O}$ \\
\hline $\mathrm{O} 1 \mathrm{~s}-2$ & 532.2 & 1.77 & 5238.10 & 9.7 & $\mathrm{Si}-\mathrm{O}$ \\
\hline $\mathrm{O} 1 \mathrm{~s}-3$ & 533.4 & 1.77 & 2622.73 & 4.9 & $\mathrm{H} 2 \mathrm{O}$ \\
\hline Si2p3 & 101.9 & 2.76 & 168.05 & 1.6 & $\mathrm{Si}-\mathrm{O}-\mathrm{C}$ \\
\hline
\end{tabular}

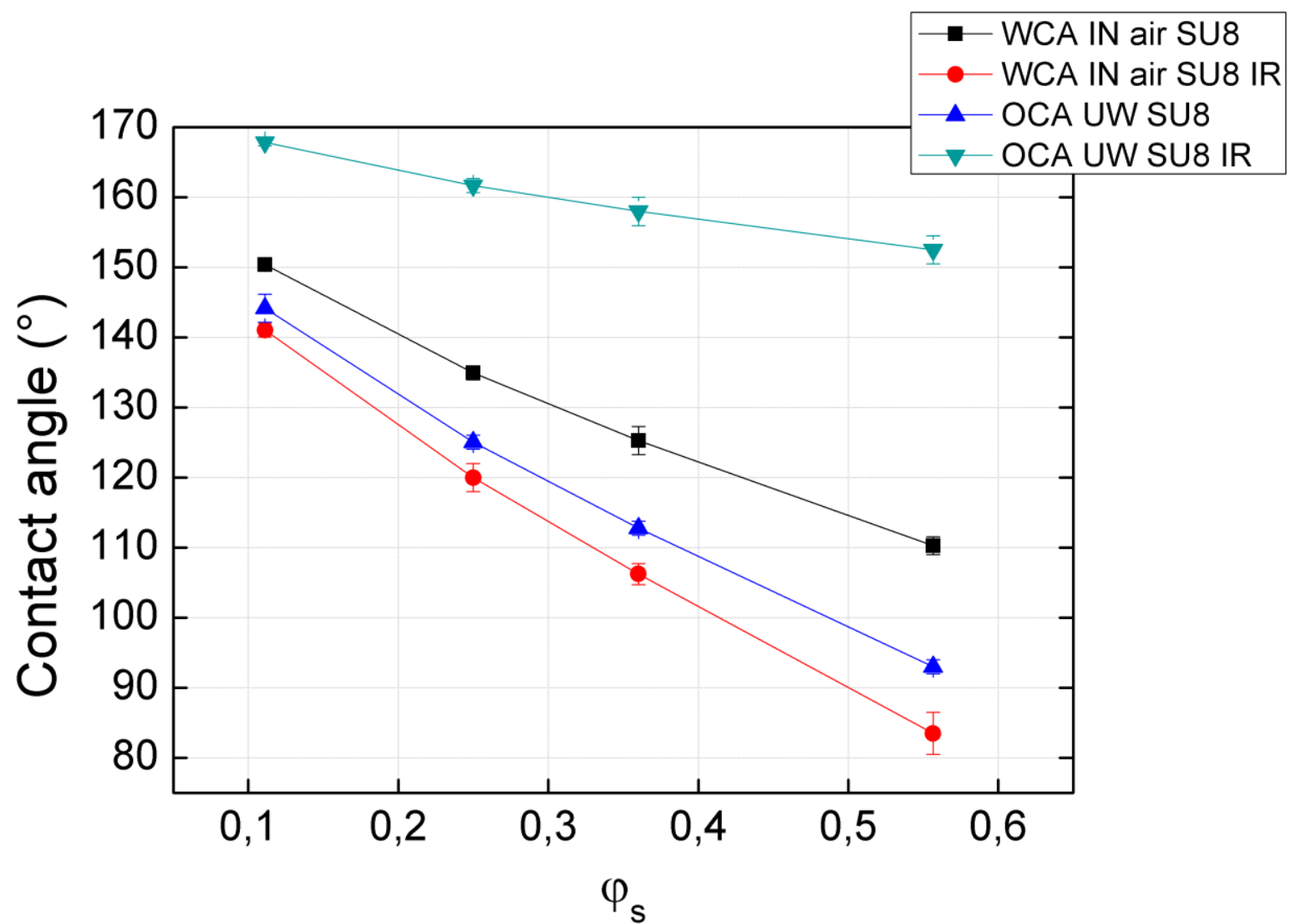

Fig S1:-Plot of the theoretical contact angle as a function of the solid fraction. Given that $\varphi s$ is 0.11 for pillars $50 \times 100,0,25$ for pillars $40 \times 40,0,36$ for pillars $42 \times 28$, and 0,55 for pillars $47 \times 16$, a reduced wettability can be predicted for smaller solid fractions, in agreement with the measured CAs. 


\section{References:-}

1. Aydil, S.C.D.a.E.S. (1996). Investigation of low temperature $\mathrm{SiO} 2$ plasma enhanced chemical vapor deposition. Journal of Vacuum Science \& Technology B: Microelectronics and Nanometer Structures Processing, Measurement, and Phenomena 14(2), 738-743. doi: 10.1116/1.588707.

2. Bixler, G.D., and Bhushan, B. (2013). Fluid drag reduction and efficient self-cleaning with rice leaf and butterfly wing bioinspired surfaces. Nanoscale 5(17), 7685-7710. doi: 10.1039/c3nr01710a.

3. Bogue, R. (2007). MEMS sensors: past, present and future. Sensor Review 27(1), 7-13. doi: doi:10.1108/02602280710729068.

4. Brown, P.S., and Bhushan, B. (2015). Bioinspired, roughness-induced, water and oil super-philic and superphobic coatings prepared by adaptable layer-by-layer technique. Sci Rep 5, 14030. doi: 10.1038/srep14030.

5. Campo, A.d., and Greiner, C. (2007). SU-8: a photoresist for high-aspect-ratio and 3D submicron lithography. Journal of Micromechanics and Microengineering 17(6), R81.

6. Caputo, G., Cortese, B., Nobile, C., Salerno, M., Cingolani, R., Gigli, G., et al. (2009). Reversibly LightSwitchable Wettability of Hybrid Organic/Inorganic Surfaces With Dual Micro-/Nanoscale Roughness. Advanced Functional Materials 19(8), 1149-1157. doi: doi:10.1002/adfm.200800909.

7. Cassie, A.B.D., and Baxter, S. (1944). Wettability of porous surfaces. Transactions of the Faraday Society 40(0), 546-551. doi: 10.1039/TF9444000546.

8. Chen, F., Song, J., Lu, Y., Huang, S., Liu, X., Sun, J., et al. (2015a). Creating robust superamphiphobic coatings for both hard and soft materials. Journal of Materials Chemistry A 3(42), 20999-21008. doi: 10.1039/C5TA05333A.

9. Chen, X., Weibel, J.A., and Garimella, S.V. (2015b). Water and Ethanol Droplet Wetting Transition during Evaporation on Omniphobic Surfaces. Sci Rep 5, 17110. doi: 10.1038/srep17110.

10. Cortese, B., Caschera, D., Federici, F., Ingo, G.M., and Gigli, G. (2014). Superhydrophobic fabrics for oilwater separation through a diamond like carbon (DLC) coating. Journal of Materials Chemistry A 2(19), 67816789. doi: 10.1039/C4TA00450G.

11. Cortese, B., D'Amone, S., Manca, M., Viola, I., Cingolani, R., and Gigli, G. (2008). Superhydrophobicity due to the hierarchical scale roughness of PDMS surfaces. Langmuir 24(6), 2712-2718. doi: 10.1021/la702764x.

12. Cortese, B., and Morgan, H. (2012). Controlling the wettability of hierarchically structured thermoplastics. Langmuir 28(1), 896-904. doi: 10.1021/la203741b.

13. Erbil, H.Y., and Cansoy, C.E. (2009). Range of applicability of the Wenzel and Cassie-Baxter equations for superhydrophobic surfaces. Langmuir 25(24), 14135-14145. doi: 10.1021/la902098a.

14. Farshchian, B., Park, S., Choi, J., Amirsadeghi, A., Lee, J., and Park, S. (2012). 3D nanomolding for lab-on-achip applications. Lab on a Chip 12(22), 4764-4771. doi: 10.1039/C2LC40572E.

15. Feng, L., Zhang, Z., Mai, Z., Ma, Y., Liu, B., Jiang, L., et al. (2004). A super-hydrophobic and super-oleophilic coating mesh film for the separation of oil and water. Angew Chem Int Ed Engl 43(15), 2012-2014. doi: 10.1002/anie.200353381.

16. Gogolides, E., Ellinas, K., and Tserepi, A. (2015). Hierarchical micro and nano structured, hydrophilic, superhydrophobic and superoleophobic surfaces incorporated in microfluidics, microarrays and lab on chip microsystems. Microelectronic Engineering 132, 135-155. doi: https://doi.org/10.1016/j.mee.2014.10.002.

17. Hao, C., Liu, Y., Chen, X., Li, J., Zhang, M., Zhao, Y., et al. (2016). Bioinspired Interfacial Materials with Enhanced Drop Mobility: From Fundamentals to Multifunctional Applications. Small 12(14), 1825-1839. doi: doi:10.1002/smll.201503060.

18. Hejazi, V., Nyong, A.E., Rohatgi, P.K., and Nosonovsky, M. (2012). Wetting transitions in underwater oleophobic surface of brass. Adv Mater 24(44), 5963-5966. doi: 10.1002/adma.201202516.

19. Herminghaus, S. (2000). Roughness-induced non-wetting. Europhysics Letters 52(2), 165-170. doi: 10.1209/epl/i2000-00418-8.

20. Herminghaus, S., Brinkmann, M., and Seemann, R. (2008). Wetting and Dewetting of Complex Surface Geometries. Annual Review of Materials Research 38(1), 101-121. doi: 10.1146/annurev.matsci.38.060407.130335. 
21. Jeong, S.-H., Nishii, J., Park, H.-R., Kim, J.-K., and Lee, B.-T. (2003). Influence of fluorine doping on SiOxFy films prepared from a TEOS/O2/CF4 mixture using a plasma enhanced chemical vapor deposition system. Surface and Coatings Technology 168(1), 51-56. doi: https://doi.org/10.1016/S0257-8972(03)00012-4.

22. Jiang, T., Guo, Z., and Liu, W. (2015). Biomimetic superoleophobic surfaces: focusing on their fabrication and applications. Journal of Materials Chemistry A 3(5), 1811-1827. doi: 10.1039/C4TA05582A.

23. Kastenmeier, B.E.E., Matsuo, P.J., and Oehrlein, G.S. (1999). Highly selective etching of silicon nitride over silicon and silicon dioxide. Journal of Vacuum Science \& Technology A 17(6), 3179-3184. doi: 10.1116/1.582097.

24. Kim, J.Y., Choi, K., Moon, D.I., Ahn, J.H., Park, T.J., Lee, S.Y., et al. (2013). Surface engineering for enhancement of sensitivity in an underlap-FET biosensor by control of wettability. Biosens Bioelectron 41, 867870. doi: 10.1016/j.bios.2012.08.036.

25. Lafuma, A., and Quere, D. (2003). Superhydrophobic states. Nat Mater 2(7), 457-460. doi: 10.1038/nmat924.

26. Lorenz, H., Despont, M., Fahrni, N., LaBianca, N., Renaud, P., and Vettiger, P. (1997). SU-8: a low-cost negative resist for MEMS. Journal of Micromechanics and Microengineering 7(3), 121.

27. Marmur, A. (2003). Wetting on Hydrophobic Rough Surfaces: To Be Heterogeneous or Not To Be? Langmuir 19(20), 8343-8348. doi: 10.1021/la0344682.

28. Michielsen, S., and Lee, H.J. (2007). Design of a Superhydrophobic Surface Using Woven Structures. Langmuir 23(11), 6004-6010. doi: 10.1021/la063157z.

29. Nemani, K.V., Moodie, K.L., Brennick, J.B., Su, A., and Gimi, B. (2013). In vitro and in vivo evaluation of SU8 biocompatibility. Mater Sci Eng C Mater Biol Appl 33(7), 4453-4459. doi: 10.1016/j.msec.2013.07.001.

30. Nishimoto, S., and Bhushan, B. (2013). Bioinspired self-cleaning surfaces with superhydrophobicity, superoleophobicity, and superhydrophilicity. RSC Advances 3(3), 671-690. doi: 10.1039/C2RA21260A.

31. Nordström, M., Rodolphe, M., Montserrat, C., and Anja, B. (2004). Rendering SU-8 hydrophilic to facilitate use in micro channel fabrication. Journal of Micromechanics and Microengineering 14(12), 1614.

32. Nosonovsky, M., and Bhushan, B. (2016). Why re-entrant surface topography is needed for robust oleophobicity. Philos Trans A Math Phys Eng Sci 374(2073). doi: 10.1098/rsta.2016.0185.

33. Palamà, I.E., D'Amone, S., Arcadio, V., Caschera, D., Toro, R.G., Gigli, G., et al. (2015). Underwater Wenzel and Cassie oleophobic behaviour. Journal of Materials Chemistry A 3(7), 3854-3861. doi: 10.1039/C4TA06787H.

34. Palamà, I.E., D'Amone, S., Biasiucci, M., Gigli, G., and Cortese, B. (2014). Bioinspired design of a photoresponsive superhydrophobic/oleophilic surface with underwater superoleophobic efficacy. Journal of Materials Chemistry A 2(41), 17666-17675. doi: 10.1039/C4TA04068F.

35. Quéré, D. (2002). Rough ideas on wetting. Physica A: Statistical Mechanics and its Applications 313(1), 32-46. doi: https://doi.org/10.1016/S0378-4371(02)01033-6.

36. Quéré, D. (2008). Wetting and Roughness. Annual Review of Materials Research 38(1), 71-99. doi: 10.1146/annurev.matsci.38.060407.132434.

37. Sackmann, E.K., Fulton, A.L., and Beebe, D.J. (2014). The present and future role of microfluidics in biomedical research. Nature 507(7491), 181-189. doi: 10.1038/nature13118.

38. Seemann, R., Brinkmann, M., Kramer, E.J., Lange, F.F., and Lipowsky, R. (2005). Wetting morphologies at microstructured surfaces. Proc Natl Acad Sci U S A 102(6), 1848-1852. doi: 10.1073/pnas.0407721102.

39. Sobiesierski, A., Thomas, R., Buckle, P., Barrow, D., and Smowton, P.M. (2015). A two-stage surface treatment for the long-term stability of hydrophilic SU-8. Surface and Interface Analysis 47(13), 1174-1179. doi: doi:10.1002/sia.5870.

40. Tuteja, A., Choi, W., Mabry, J.M., McKinley, G.H., and Cohen, R.E. (2008). Robust omniphobic surfaces. Proc Natl Acad Sci U S A 105(47), 18200-18205. doi: 10.1073/pnas.0804872105.

41. Wenzel, R.N. (1936). RESISTANCE OF SOLID SURFACES TO WETTING BY WATER. Industrial \& Engineering Chemistry 28(8), 988-994. doi: 10.1021/ie50320a024.

42. Xu, B., Jin, Q., and Zhao, J. (2007). Multi-layer SU-8 based micro dispensing system for microarray immunoassay. Sensors and Actuators A: Physical 135(1), 292-299. doi: https://doi.org/10.1016/j.sna.2006.07.003.

43. Yong, J., Chen, F., Fang, Y., Huo, J., Yang, Q., Zhang, J., et al. (2017). Bioinspired Design of Underwater Superaerophobic and Superaerophilic Surfaces by Femtosecond Laser Ablation for Anti- or Capturing Bubbles. ACS Appl Mater Interfaces 9(45), 39863-39871. doi: 10.1021/acsami.7b14819.

44. Zhang, J., Zhou, W.X., Chan-Park, M.B., and Conner, S.R. (2005). Argon plasma modification of SU-8 for very high aspect ratio and dense copper electroforming. Journal of the Electrochemical Society 152(10), C716-C721. doi: $10.1149 / 1.2034519$. 
45. Zheng, L., Wu, X., Lou, Z., and Wu, D. (2004). Superhydrophobicity from microstructured surface. Chinese Science Bulletin 49(17), 1779-1787. doi: 10.1007/bf03183400. 